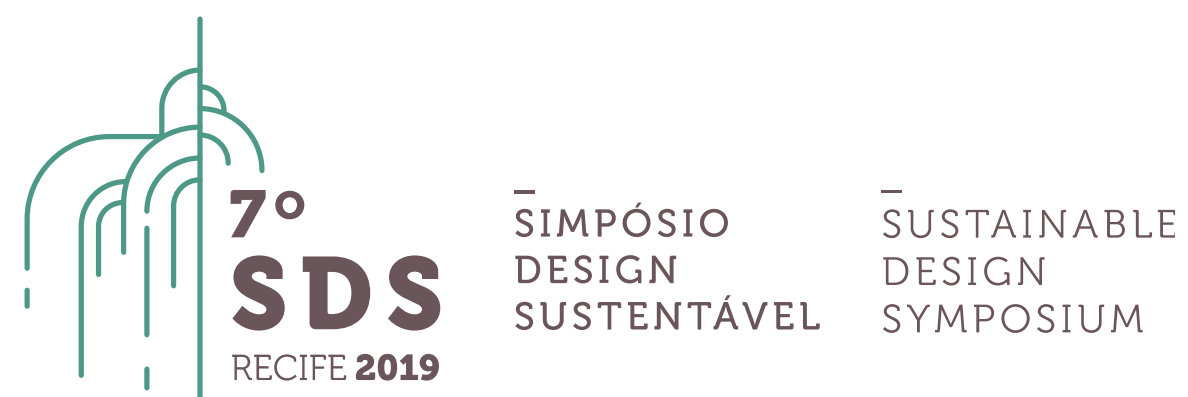

\title{
A adesão da fibra de algodão orgânico branco e o naturalmente colorido ao mercado da moda sustentável
}

\author{
Semira Guerra Casé da Cunha ${ }^{1}$, Alfredo Jefferson de Oliveira ${ }^{2}$ \\ ${ }^{1}$ Pontifícia Universidade Católica do Rio de Janeiro, PPG Design - semiracase@gmail.com \\ ${ }^{2}$ Pontifícia Universidade Católica do Rio de Janeiro, PPG Design - afferson@puc-rio.br
}

Resumo. O presente artigo propõe observar os gargalos do sistema agroecológico do algodão, bem como a tecnologia do algodão naturalmente colorido na cadeia produtiva têxtil e de confecção, e como esta se posiciona em relação à tendência global de desenvolvimento sustentável que vem se consolidando como um novo segmento no mercado brasileiro, à medida que a conscientização das questões ambientais se coloca como um valor. Por meio de pesquisa bibliográfica e utilização de técnicas de observação e entrevistas com atores desta cadeia produtiva, a pesquisa de caráter exploratório com abordagem qualitativa trata da utilização dessa matéria-prima no mercado brasileiro sobre a perspectiva de desenvolvimento e expansão do consumo de produtos de moda ecologicamente corretos com o objetivo de localizar e analisar a aplicabilidade do material e a que tipo de segmentação se destina esse tipo de produto no mercado nacional.

Palavras-chave. Materiais sustentáveis; Algodão orgânico; Naturalmente colorido; Cadeia produtiva; Mercado da moda.

\begin{abstract}
The present article aims to examine impasses in the cotton agroecosystem, as well as to investigate how the naturally colored cotton technology, which is now part of the textile and clothing industry production chain, is positioned in the global trend of sustainable development. This trend has been consolidating as a new segment in the Brazilian market since the awareness of environmental issues is increasingly valued. Through a bibliographic survey and the use of observation and interviews techniques along people who act in this productive chain, an exploratory research with a qualitative approach will deal with the use of this raw material in the Brazilian market from the perspective of development and expansion in the consumption of ecologically oriented fashion products. The study focuses on locating and analyzing the applicability of the material, in order to understand for what segmentation this product type is destined to in the national market.
\end{abstract}


Keywords. Sustainable materials; Organic Cotton; Naturally colorful; Productive chain; Fashion market.

\section{Introdução}

Há quarenta e sete anos, a problemática sobre o comprometimento dos recursos naturais básicos do planeta como a água, a qualidade do ar e do solo, causados por um perverso modelo de crescimento econômico foram anunciados pela primeira vez por ambientalistas na primeira Conferência das Nações Unidas sobre o Ambiente Humano, em Estocolmo. A reunião que contou com a presença de muitos chefes de estado continua em pauta na sociedade até os dias de hoje. A discussão em torno do assunto ganhou força, se avolumou e expandiu-se para além das questões ambientais, trazendo à tona também os impactos sociais causados pelos mesmos padrões de desenvolvimento.

O conceito atrelado ao desenvolvimento sustentável penetrou nas mais diversas áreas do conhecimento e avança como um valor universal em potencial, como afirma Manzini e Vezzoli (2011). Concentrando as expectativas no campo design, meios de produção e consumo, especificamente na indústria da moda - uma das maiores, mais poluentes e desiguais do mundo, como conciliar os interesses e demandas por resultados econômicos dessa indústria às diretrizes do desenvolvimento sustentável? Parece razoável a ideia de que a valorização dos materiais mais sustentáveis ou ecologicamente corretos possa conciliar tais interesses, por vezes considerados antagônicos:

No contexto econômico e normativo que até agora conhecemos, verifica-se de fato uma profunda divergência entre racionalidade econômica (baseada na procura da eficiência econômica) e racionalidade ecológica (com que se deve buscar a eco-eficiência, isto é, a contenção do consumo dos recursos ambientais): Quem persegue a primeira quase nunca consegue atingir a segunda. Dois fatores fundamentais pressionaram nesta direção: o baixo custo dos recursos ambientais e a correlação positiva entre crescimento econômico e crescimento dos consumos de recursos naturais (MANZINI; VEZZOLI, 2011, p.50).

Partindo dessa premissa, e sobre a perspectiva de redução de impactos, a substituição dos materiais pode levar a perceber benefícios com rapidez por causa dos volumes de venda e não exigir grandes transformações aos negócios, além disso, a aplicação de determinada matériaprima ao produto é uma decisão atrelada ao design (FLETCHER; GROSE, 2011). O algodão, por sua vez, é uma das fibras mais utilizadas pela indústria da moda e o seu uso permeia a história da indumentária durante séculos. No entanto, a produção e o consumo da fibra vêm apresentando queda em todo o mundo em detrimento da abertura do mercado para as fibras sintéticas e seu baixo custo. Apesar disso, o Brasil está entre os cinco maiores produtores de algodão branco do mundo, e entre os maiores consumidores. Mas a cotonicultura tradicional também apresenta sérios impactos ambientais, pois no processo de otimização da produtividade é necessário a aplicação de altos níveis de defensivos agrícolas no combate às pragas, contaminando solos, águas e ar - por meio da aplicação de fertilizantes em vôos, além do uso dos agrotóxicos oferecer riscos de intoxicação à trabalhadores rurais e a população do entorno. $O$ uso intenso de produtos químicos não se limita apenas à atividade agrícola, eles também estão presentes na etapa de acabamento durante o processo industrial, onde os fios passam por alvejamento e tingimento.

A aplicação do sistema de produção orgânica ou sistema sustentável, surge como uma possibilidade para o algodão como forma de introduzir os valores atrelados ao desenvolvimento sustentável ao produto. Contudo, esse modelo apresenta muitas limitações em relação ao modelo agroindustrial, o que gera escassez na oferta da pluma e dos produtos subsequentes. Para Souza (2000), o mercado de têxteis orgânicos está em desequilíbrio e por essa razão, deve permanecer como um nicho, apesar da crescente demanda, inclusive no mercado brasileiro. 
Além do algodão branco ou natural (coloração correspondente ao off white da indústria), também está disponível no mercado o algodão naturalmente colorido, onde a pluma já nasce colorida na planta. Apesar do desconhecimento da espécie para muitos, esta não é fruto de inovação biotecnológica, pois está presente na natureza há mais de 4.500 anos e foi renegada em razão da inclinação da indústria têxtil para o algodão branco (LIRBÓRIO, 2015). Além disso, essa espécia possuía fibras muito curtas e inadequadas para a produção de têxteis. No Brasil, o melhoramento genético da fibra - que consiste em combinações genéticas de uma mesma espécie, foi desenvolvido pela Embrapa (Empresa Brasileira de Pesquisa Agropecuária) e as sementes estão disponíveis no mercado desde o começo dos anos 2000, porém, em uma cartela de cores limitada e com pequenas variações a partir do marrom. Introduzir o algodão naturalmente colorido no sistema de produção agroecológico foi um caminho encontrado para agregar mais valor ao produto e potencializar o fato de que esses têxteis não passam pela etapa de tingimento químico, em virtude disso, recebem a denomicação de produto orgânico.

Mesmo com uma cadeia produtiva incipiente no Brasil, o mercado de produtos de algodão orgânico deve se manter em crescimento. Para o diretor executivo da ABVTEX (Associação Brasileira do Varejo Têxtil), as novas gerações vêm com uma forte demanda de sustentabilidade, querem saber da origem dos produtos e como foram produzidos (EMBRAPA, 2017). Dentro desse cenário, esse estudo aborda a utilização dessa matéria-prima no mercado brasileiro sobre essa perspectiva de desenvolvimento e expansão do consumo de produtos de moda ecologicamente corretos, assim como o conceito de ecodesign está sendo introduzido na indústria têxtil e de confecção. A pesquisa de caráter exploratório com abordagem qualitativa, objetiva verificar a aplicabilidade e a segmentação desse tipo de produto no mercado nacional utilizando fontes bibliográficas e técnicas de observação e entrevistas com atores desta cadeia produtiva.

\section{A produção agrícola da pluma do algodão orgânico no Brasil}

A agricultura está entre as principais atividades econômicas do Brasil, e desde os primeiros séculos da colonização, o algodão está entre os produtos produzidos em larga escala no país. A produção algodoeira do Brasil atingiu o seu auge na segunda metade do século XVIII, quando liderou a lista dos produtos de exportação e foi chamado de "ouro branco". Nesse período, a produção se concentrava na região Nordeste (ANDRADE, 2011 [1963]; FURTADO, 2005; PRADO JUNIOR, 2004 [1942] apud LIRBÓRIO, 2015). Contudo, na década de 1980, a cotonicultura foi acometida pelo surto do bezouro bicudo, uma das principais ameaças à lavoura do algodão. Desde então, a produção algodoeira no Brasil passou por altos e baixos, e no decorrer dos anos, se transformou, sofreu deslocamentos e se restabeleceu.

O algodão branco commodity, apesar do seu lugar e relevância na economia do país, se trata de uma matéria-prima que causa muitos prejuízos ao meio ambiente. $\mathrm{O}$ algodão orgânico, por sua vez, é produzido dentro de princípios de qualidades mais abrangentes que superam os aspectos referentes à qualidade técnica e viabilidade econômica do algodão convencional e aparece nesse contexto como uma oportunidade para ocupar uma modesta, mas crescente demanda por produtos orgânicos. Essa demanda por produtos orgânicos está presente, inclusive, tanto no setor de produtos primários quanto nos secundários, sendo possível observar sua presença em feiras livres e supermercados, de modo que estão ocupando uma pequena fatia do mercado. Uma tendência de consumo que também encontra aderência em outras categorias, como os produtos de limpeza e cosméticos, por exemplo.

A cotonicultura orgânica no Brasil cresce a uma média de $20 \%$ ao ano, no entanto, o sistema de produção agroecológico demanda mais cuidados e por isso possui preço mais elevado, uma média de 30\% a 50\% superior (RETAMIRO; SILVA; VIEIRA, 2013). De acordo com empresária 
do setor, as áreas para o cultivo do algodão orgânico variam em torno de 1 a 2 ha, são pequenas áreas para que seja possível perceber a infestação de pragas, etc.

Além do algodão branco como um insumo relevante para a cadeia produtiva têxtil, surge no final na década de 1980, após a crise do algodão causada pela praga do bezouro, uma nova oportunidade de inovação para a cotonicultura com a tecnologia do algodão naturalmente colorido desenvolvida pela Embrapa Algodão, empresa brasileira sediada em Campina Grande-PB (CARVALHO; ANDRADE; SILVA FILHO, 2011 apud LIRBÓRIO, 2015). O melhoramento genético do algodão naturalmente colorido resultou em maior resistência, alongamento da fibra e melhor toque. Entretanto, a pluma desse algodão possui pouca abrangência em relação às cores, limitando-se também à pequenas variações de tons terrosos divididas em cinco cultivares: marrom, rubi, safira, topázio e verde.

Figura 1 - Variedade do algodão naturalmente colorido

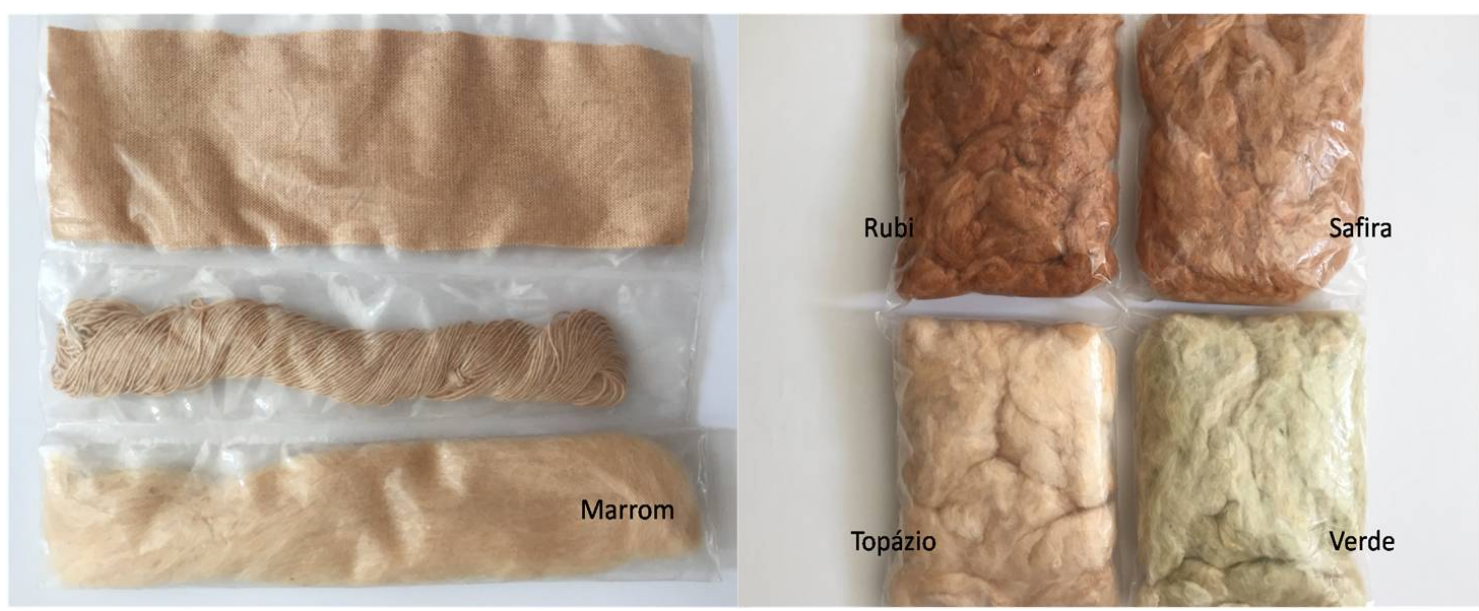

Fonte: Elaborado pelo autor (2019)

Atualmente, a produção do algodão naturalmente colorido se concentra nos estados da Paraíba e Ceará, no entanto, sua cultura é indicada para as condições de todo semiárido brasileiro, incluindo a região Nordeste e Sudeste, especificamente o Norte de Minas Gerais. Já as sementes da planta são doadas pela Embrapa para cooperativas e pequenos agricultores isolados, como afirma analista e engenheiro agrônomo da Embrapa. O algodão naturalmente colorido, ou algodão da Paraíba, como também é conhecido devido ao selo de indicação geográfica concedido pelo INPI em 2012, também é produzido dentro do sistema agroecológico, e, portanto, um produto orgânico. Os produtos orgânicos, ecológicos e socialmente corretos, como também são comercialmente chamados, costumam evidenciar as características que os diferencia dos demais através dos selos certificadores.

Essas certificações são realizadas por respeitadas agências, públicas ou privadas, e são importantes inclusive para "coibir ações oportunistas por parte dos agentes produtivos", como alerta Souza (2000, p.102), e assegurar a integridade e a origem do produto para o consumidor, ou seja, só os produtos certificados apresentam a garantia da propriedade orgânica. Dois selos são mais recorrentes na certificação do algodão orgânico no Brasil, o selo ECOCERT ${ }^{a}$, reconhecido em mais de 80 países, e o brasileiro IBD $^{b}$, que atua em toda América Latina com certificações para produtos orgânicos aceitos pelo mercado internacional. Nesse caso, todas as etapas do plantio

\footnotetext{
${ }^{a}$ Organização de certificação de produtos orgânicos, fundada na França e que atua no Brasil desde 2001. Disponível em: http://brazil.ecocert.com/quem-somos/index.html

${ }^{\mathrm{b}}$ Empresa 100\% brasileira que desenvolve atividades de inspeção e certificação agropecuária, de processamento e de produtos extrativistas, orgânicos, biodinâmicos e de mercado justo. Disponível em: http://ibd.com.br/pt/Default.aspx
} 
passam por inspeção e supervisão dessas agências para averiguar o cumprimento das exigências características do sistema agroecológico, pois assim como a pluma de cor branca, a pluma do algodão naturalmente colorida não é necessariamente orgânica. Já a comercialização dessas fibras se dá no mercado interno e externo, e geralmente por meio de contratos, onde o comprador assume antecipadamente o compromisso de compra da pluma com o agricultor.

\subsection{Vantagens sociais, ambientais e econômicas}

No Brasil, a cotonicultura orgânica quer do algodão branco ou do naturalmente colorido está sendo produzida apenas por cooperativas agrícolas ou pequenos agricultores familiares, devido às demandas do manejo que esse modelo exige. Essas limitações técnicas favorecem a inclusão dos pequenos agricultores a essa cadeia produtiva, proporcionando maior ganho econômico em relação ao obtido com os produtos produzidos no sistema convencional. Há ainda melhoria na qualidade de vida ao eliminar os riscos de contaminação pelo uso de agrotóxicos na lavoura, já que na agricultura orgânica são utilizados apenas defensivos naturais. Na esfera ambiental, podemos destacar a valorização da biodiversidade e a não utilização de água para a irrigação, visto que para o plantio de uma safra anual as águas das chuvas são suficientes para garantir a produtividade, pois o algodão responde bem a climas secos. E como mencionado anteriormente, não há o uso de agrotóxicos na agricultura, e, portanto, a não contaminação do ar, solo, rios e águas subterrâneas.

Além dos pilares básicos que constituem o conceito de desenvolvimento sustentável, Retamiro et al. (2013) aborda ainda outras dimensões que podem ser aplicadas à sustentabilidade, no caso da cadeia produtiva do algodão orgânico da Justa Tramac ${ }^{c}$, como a sustentabilidade espacial, cultural e política. Na sustentabilidade espacial, os autores observam que a Justa Trama se adequou às condições locais e manteve as configurações iniciais do ambiente rural e urbano, onde nenhuma das partes migrou para a outra área a fim de reduzir custos ou otimizar a logística da cooperativa - o que também não quer dizer que essa iniciativa não origine impactos em outras dimensões. Na questão da sustentabilidade cultural se coloca o respeito aos saberes culturais, onde a cooperativa valoriza e explora as habilidades empíricas da população local em lidar com insumos produzidos na região, como as sementes que dão origem a botões e biojóias. E finalmente a sustentabilidade política, na qual os autores destacam a consolidação dos processos democráticos na gestão das cooperativas.

\section{Cenários na indústria}

\subsection{Fiação}

Após o beneficiamento - descaroçamento e limpeza das impurezas da pluma, o produto segue o fluxo da cadeia produtiva para a etapa de fiação. Nesta etapa, o produto agrícola passa pela primeira grande transformação industrial onde os fardos de pluma são transformados em bobinas de fio. Todo o processamento necessário dessa etapa se dá igualmente para ambos os tipos de algodão, contudo, é necessária a limpeza do maquinário para receber a pluma orgânica para não haver contaminação, se esta processou anteriormente o algodão convencional. 0 monitoramento de todo o processo de fiação do algodão orgânico é feito pelas mesmas agências certificadoras que acompanharam a produção agrícola da pluma.

A oferta de produtos nessa indústria é definida essencialmente por parâmetros de qualida-

\footnotetext{
${ }^{\mathrm{C}}$ Cadeia produtiva no segmento de confecção da economia solidária, articulando 600 cooperados/associados, em cinco estados: Rio Grande do Sul, Mato Grosso do Sul, Minas Gerais, Ceará e Rondônia. Mais informações em: https://www.justatrama.com.br/sobre-nos/
} 
de referentes ao toque e espessura dos fios. Os fios de algodão penteado são obtidos a partir das fibras de algodão mais longas, resultando em fios mais finos e macios. Já os fios cardados são produzidos a partir das fibras mais curtas, gerando fios mais grossos e ásperos, mas ambos atendem a públicos e mercados distintos. Contudo, não há distinção dessas especificações para os fios comuns e os orgânicos.

Além da qualidade da fibra oriunda da produção agrícola, é relevante frisar a importância de a fiação também dispor de equipamentos modernos para produzir fios com mais qualidade, visto que a indústria têxtil investe fortemente em tecnologia e demanda insumos à altura para manter os altos padrões de qualidade exigidos pelo mercado. No Brasil, há no setor de fiação, empresas de pequeno, médio e grande porte (SOUZA, 2000), o que demonstra capacidades variadas na absorção dos atributos tecnológicos. De acordo com empresária ${ }^{d}$ do setor de algodão orgânico que relata experiência com o algodão orgânico naturalmente colorido, o processo de fiação é sempre uma grande dificuldade: "[...] começamos a fiar em fiações que estavam quebrando, fiações pequenas que faziam fio de má qualidade, então a gente teve que baixar o nível por causa da estrutura que a gente tinha, as circunstâncias."

Essa problemática não está relacionada à incapacidade técnica e tecnológica da indústria brasileira em produzir fios de alta qualidade, mas ao fato das grandes empresas de fiação exigir maiores volumes para fiar o algodão orgânico, seja o branco ou o colorido. Para Farias (2010), essa é uma das etapas mais problemáticas porque além das quantidades serem muito pequenas, há ainda o processo de limpeza das máquinas antes e após o uso, e que por isso as empresas não se interessam em realizar o serviço. A interrupção no funcionamento do maquinário certamente acarreta queda na produtividade das empresas e por isso eleva os custos do serviço. Souza (2000, p. 96) ainda pontua outra assimetria característica dessa etapa: "[...] ocorre um forte desequilíbrio entre oferta e demanda, pela sazonalidade da produção de algodão e a constância de seu consumo industrial." Esse impasse talvez explique porque algumas empresas brasileiras prefiram importar fios de outros países como Peru, Turquia e Índia, por exemplo.

Como a produção ainda é muito pequena, a fiação do algodão $100 \%$ orgânico continua sendo terceirizada e realizada por pequenas e médias empresas, como no contexto citado anteriormente. Isso ocorre com os fios utilizados e vendidos pela Justa Trama, Coopnatural e Natural Cotton Color, da Paraíba. Contudo, a configuração do mercado de algodão orgânico pode estar em processo de transformação com a abertura e o interesse de algumas empresas pela pluma do algodão branco $100 \%$ orgânico. É o caso da Norfil, empresa de grande porte do setor de fiação situada em João Pessoa.

Atualmente, a empresa está comprometida em adquirir toda a produção disponível da pluma de algodão orgânico produzido pela Coopnatural. O objetivo da Norfil está em desenvolver um fio misto mais acessível e comercial, contendo na sua composição $5 \%$ de fibra orgânica e $95 \%$ do algodão tipo $\mathrm{BCl}^{\mathrm{e}}$, produto desenvolvido para a empresa de malharia Menegotti. Para empresária, a parceria com as grandes empresas são imprescindíveis para o desenvolvimento dessa cadeia produtiva, mas explica que o setor de fios e têxteis precisam se aproximar, e cooperar para o desenvolvimento da produção agrícola, com financiamentos, etc. Para ela, a fibra de cor branca oferece mais possibilidades, inclusive para o tingimento. Além das possibilidades de transformação em relação às fibras naturalmente coloridas porque o mercado de fibras de cor branca já está consolidado e é amplamente aceito e utilizado por todos os segmentos do setor têxtil.

\footnotetext{
${ }^{\mathrm{d}}$ Em entrevista realizada pelo autor em 08/02/2019.

e Algodão BCI - A Better Cotton Initiative (BCI) é uma organização suíça associada a entidades da cadeia produtiva da moda que dá formação e suporte a agricultores, a fim de melhorar as práticas do cultivo, as condições de trabalho e reduzir o uso de insumos agrícolas como a água e os agrotóxicos. De acordo com os princípios do projeto, é consentido o uso de sementes geneticamente modificadas, transgênicas.
} 


\subsection{Tecelagem}

A tecelagem é a fase subsequente à etapa de fiação e onde os fios são utilizados na construção dos tecidos. Há nesta etapa, uma ampla concentração de processos devido à variedade de fibras, gramaturas e estruturas existentes, sobretudo, quando esta inclui a fase de acabamento dos têxteis. Mas os produtos estão divididos basicamente em duas categorias: os tecidos planos e a malharia. A produção dos têxteis de algodão se dá de maneira igual para os fios comuns e os orgânicos, com a atenção para o processo de limpeza do maquinário citado por Souza (2000) e Farias (2010), que, de acordo com empresária, não é necessário na etapa de tecelagem, sendo o processo de certificação encerrado na fiação. Esse contrassenso entre o que pode vir a ser uma recomendação de um órgão ou legislação e o que de fato está sendo feito na prática, pode colocar em risco a reputação dos selos certificadores, do produto e a da própria empresa.

A configuração desta etapa da cadeia produtiva do algodão $100 \%$ orgânico funciona no mesmo modelo da etapa anterior. As tecelagens não adquirem o fio do algodão para produzir os tecidos e vendê-los, elas apenas prestam os serviços às empresas confeccionistas e as que também comercializam os têxteis orgânicos (FARIAS, 2010). Por ainda não ter alcançado escalas significativas, tanto o mercado produtor como o mercado consumidor, está voltado para os pequenos empreendedores. Foram observadas atualmente no mercado brasileiro, cinco empresas fornecedoras de matéria-prima, mas apenas três delas divulga e comprova que os tecidos são certificados.

Como todo o processo de produção dos têxteis orgânicos representa custos mais elevados para os fabricantes, entende-se a importância de expor informações a respeito das qualidades do produto e estabelecer uma relação de transparência por meio do selo de certificação. Os selos são indicadores que asseguram ao consumidor a procedência dos materiais e as condições em que os produtos foram fabricados. As informações podem consolidar aspectos positivos dos produtos e o não esclarecimento delas, levantar dúvidas e suspeitas no consumidor a respeito da veracidade do título "orgânico" conferido ao produto, de modo a colocar em risco a reputação da empresa e qualquer relação de confiança existente entre o consumidor/cliente e a mesma.

Em relação à oferta de cores dos têxteis orgânicos, vale lembrar que além das cores que estão disponíveis no algodão naturalmente colorido, existe a possibilidade do tingimento para os tecidos "brancos" ou in natura com os corantes ou pigmentos naturais/vegetais, estes, capazes de conservar a propriedade orgânica dos tecidos sem causar sérios danos ao meio ambiente. Algumas pequenas empresas estão investindo nesse segmento com a oferta de produtos e serviços de tingimento e estamparia artesanal como a Etno Botânica, Mattricaria, e outras. Mas a informação sobre a obtenção das cores do tecido orgânico também requer atenção do fabricante, visto que os procedimentos exigidos para a produção dos produtos orgânicos como a não utilização de produtos químicos, devem ser conduzidos preferencialmente até a etapa de acabamento dos têxteis para que todo o processo do começo da cadeia produtiva se justifique. Souza (2011), inclusive, classifica os têxteis orgânicos como bens de crença porque os seus atributos não podem ser bem avaliados pelo consumidor devido ao desencontro de informações sobre o produto, considerando que o prestígio do ofertante, a marca, e a imagem pública dos orgânicos é que impulsionam a compra.

Dentre os tipos de têxteis fabricados em algodão orgânico que se destacam entre os fornecedores, estão a malha fio 30 - muito indicada para a fabricação de camisetas, e a tela ou algodão cru, tecido também utilizado em ecobags. Esses dois tipos de matéria-prima são normalmente empregados em produtos básicos, de baixo custo e fluxo frequente, o que de alguma maneira restringe a aplicação do algodão orgânico a outras linhas de produtos e segmentos. Todavia, com 
projeto $^{f}$ assinado pela Natural Cotton Color em parceria com o Senai-SP para o desenvolvimento de novos materiais têxteis em algodão orgânico naturalmente colorido, o produto pode ganhar mais projeção ao ampliar o alcance a outros mercados em potencial com tecidos mais elaborados para linhas como camisaria e alfaiataria, por exemplo.

\section{Utilização da matéria-prima e propostas de produtos}

Assim como na indústria têxtil, as confecções brasileiras também são compostas por empresas de pequeno, médio e grande porte. De acordo com a Abit $^{\mathrm{g}}$ (Associação Brasileira da Indústria Têxtil e de Confecção), mais de $80 \%$ delas são de pequenas e médias proporções. Sobre a mesma expectativa do setor têxtil, as pequenas empresas de confecção funcionam com baixos atributos tecnológicos. Adotar processos mais sustentáveis, como o uso de energia renovável, por exemplo, requer maiores investimentos em tecnologia, considerando que as máquinas de costura e demais equipamentos utilizados na produção da maioria das confecções representam valores relativamente baixos. Além disso, como as facções ${ }^{h}$ prestam serviços para outras empresas e não possuem contato com o cliente final, acabam ficando à margem dessas demandas relativas à sustentabilidade.

Algumas empresas, marcas e designers desenvolvem produtos adotando o uso de determinadas matérias-primas como forma de estarem inseridas no contexto da sustentabilidade. Uma tendência que já pode ser observada em todos os segmentos de mercado - com destaque para o feminino e infantil, além do setor de roupas íntimas. Como a oferta de algodão orgânico no mercado brasileiro ainda é muito deficiente, porém, em processo de desenvolvimento, boa parte das apostas em vestuário de algodão $100 \%$ orgânico é feita por pequenas empresas e designers empreendedores, reafirmando a condição da moda sustentável como nicho de mercado.

O valor de entrega que permeia o comércio das roupas infantis nesse campo está associado à saúde e bem-estar dos bebês, onde se destaca a questão do toque e do contato da pele com uma matéria-prima livre de produtos químicos. De acordo com esses valores, o consumidor possui a crença citada por Souza (2011) de que o usuário/criança esteja sendo beneficiado pelo uso do produto, mesmo que não haja consenso sobre os efeitos das substâncias químicas presentes nas roupas e o quão prejudicial elas podem ser à saúde humana. Foram observadas quatro marcas de vestuário infantil de algodão orgânico no mercado brasileiro (empresa $A, B, C$ e D), contudo, apenas a empresa $C$ não apresenta selo de certificação na loja online ou informações na página sobre a origem do algodão utilizado em parte dos produtos oferecidos pela marca.

Todas as marcas observadas e citadas acima estão inseridas no comércio varejista online, com exceção da empresa B que atua no comércio atacadista. Os produtos, por sua vez, são destinados a crianças de 0 a 10 anos e possuem preço médio pouco acima do vestuário de algodão convencional. A malharia é o tipo de tecido adotado por essas marcas devido aos parâmetros de conforto e mobilidade que o material proporciona ao público infantil. Com exceção da empresa $D$, todas utilizam o algodão branco e o naturalmente colorido $100 \%$ orgânico, e exploram predominantemente a estamparia corrida e localizada em silk screen. No entanto, a marca A investe mais nas cores e se distancia mais da ideia recorrente de que os produtos ecologicamente corretos não são visualmente atraentes, mesmo que possuam limitações em relação ao uso indiscriminado de alguns recursos explorados no vestuário convencional.

\footnotetext{
${ }^{\mathrm{f}}$ Matéria exibida no programa Bom Dia PB: http://g1.globo.com/pb/paraiba/bom-dia-pb/videos/t/edicoes/v/empresasque-trabalham-com-algodao-colorido-ganharam-um-concurso-do-senai-nacional/6742102/

${ }^{\mathrm{g}}$ Cartilha Indústria Têxtil e de Confecção Brasileira - Cenários, Desafios, Perspectivas e Demandas, disponível em: https://www.abit.org.br/conteudo/links/publicacoes/cartilha_rtcc.pdf

${ }^{\mathrm{h}}$ Empresa terceirizada e que não desenvolve produtos, apenas produz para outras confecções.
} 
Já a abordagem da moda feminina sustentável está centrada nos valores sociais e ambientais. O impacto da geração de resíduos no meio ambiente, a questão do comércio justo, a valorização do trabalho manual e artesanal e a apreciação da natureza foram observadas nas propostas de valor de quatro marcas (empresas E, F, G e H). Essas propostas estão em acordo com um consumidor mais maduro, consciente, informado e relativamente engajado. Todas as marcas demonstram transparência quando informam a origem da matéria-prima ou apresentam o selo de certificação. E em sua maioria, utilizam como matéria-prima os tecidos planos fabricados no Brasil, diferentemente das marcas infantis que exploram muito a malharia e até importam matéria-prima do Peru.

A comercialização dos produtos dessas marcas está toda direcionada para o comércio varejista online, mas com preço médio muito acima do praticado por empresas do mesmo porte que comercializam produtos semelhantes, mas sem pegada ecológica, concomitantemente, preços equivalentes aos praticados no mercado convencional de moda de luxo, mas sem a estrutura, e o aporte comercial e publicitário comuns a essas empresas. As propostas de produtos das marcas $\mathrm{E}$, F, G e H possuem características muito semelhantes: são produzidos em escalas reduzidas; não possuem coleções baseadas nas estações do ano; fazem uso de tecidos de fibras naturais e sintéticas, entre eles o algodão 100\% orgânico "branco" e o naturalmente colorido; exploram os tingimentos naturais; as peças são atemporais e predominantemente lisas; e apresentam modelagens amplas e estruturadas construídas na alfaiataria.

Embora o algodão orgânico naturalmente colorido tenha ocupado as passarelas das últimas edições do Brasil Eco Fashion Week, este ainda é um material muito utilizado no artesanato. O uso desses têxteis se aplica ao vestuário e a outros artefatos como brinquedos, bolsas, entre outros, mas possuem valores muito baixos em relação aos produtos mencionados anteriormente. Nesse caso, a diferença não está apenas no design, mas na origem da própria matéria-prima. 0 material desses produtos encontrados em mercados e feiras de artesanato do estado da Paraíba e estados vizinhos, por exemplo, não são certificados ou não foram produzidos de acordo com as condições do sistema agroecológico, e, portanto, não são considerados ou reconhecidos como produtos orgânicos. Essa situação gera confusão entre as nomenclaturas produtos "naturais" e "orgânicos", carecendo que as marcas atuem mais fortemente na informação dessas diferenciações e exerçam um papel mais ativo como agente educador no processo de formação de público consumidor.

\section{Conclusão}

Acredita-se que a demanda por produtos orgânicos no Brasil e no mundo representa uma mudança comportamental nos padrões de consumo da sociedade, mesmo que ainda muito pautado pelos bens materiais, e não menos por isso, uma tendência intimamente ligada à atividade projetual do designer. No entanto, a indústria têxtil brasileira está em processo de adaptação a esses novos valores que norteiam o futuro da produção industrial, e que demonstra resistência em relação ao algodão orgânico devido à incompatibilidade entre os modelos de produção e a lógica de um mercado ainda muito orientado pela questão do preço, escala de produção e volume de vendas. Em função disso, a indústria privilegia outros materiais também considerados mais sustentáveis, mas com preços mais competitivos, como o algodão reciclado e a malha PET.

Essa problemática inviabiliza projetos de marcas e de linhas de produtos com maior abrangência, e encontra-se restrito ao mercado de luxo na moda feminina e incorporado a um nicho ainda menor e com alcance limitado, o de produtos de moda ecologicamente corretos. O distanciamento entre esses mercados abre espaço para que o designer promova o diálogo entre essas abordagens e propostas de produtos construindo novos paradigmas para o consumo e uso de produtos de moda, e atue na desconstrução do conceito de que os produtos ecologicamente cor- 
retos são limitados e pouco atraentes.

\section{Referências}

ARADEFE MALHAS (Santa Catarina). Produtos: Ecológicos/PET. 2019. Disponível em: <https://aradefe.com.br/>. Acesso em: 27 abr. 2019.

BRISA (Porto Alegre). Brisa: Sobre. $2019 . \quad$ Disponível em: <https://www.brisaslowfashion.com/sobre>. Acesso em: 20 maio 2019.

ECOFANTE (São Paulo). Ecofante: Nossos Produtos. 2019. Disponível em: <https://www.ecofante.com.br/>. Acesso em: 20 maio 2019.

EMBRAPA. Cadeia produtiva do algodão orgânico debate estratégias para aumentar produção. 2017. Acesso em: <https://www.embrapa.br/busca-de-noticias/-/noticia/28873222/cadeiaprodutiva-do-algodao-organico-debate-estrategias-para-aumentar-producao>. Acesso em: 20 abr. 2019.

ENVIDO (Porto Alegre). Envido: Moda que transforma. 2019. Disponível em: <https://envido.com.br/>. Acesso em: 20 maio 2019.

ETNO BOTÂNICA (Minas Gerais). Etno Botânica - Corantes e Pigmentos Naturais: Algodão Orgânico. 2019. Disponível em: <https://etnobotanica.com.br/>. Acesso em: 20 maio 2019.

FARIAS, Paulo Sérgio Cunha. Os circuitos espaciais de produção e os círculos de cooperação do algodão colorido e derivados da Paraíba (2000-2008): Uma dimensão geográfica da flexibilização do produto, da produção e do consumo de moda, fibras, têxteis e confecções. 2010. 309 f. Tese (Doutorado) - Curso de Geografia, Departamento de Ciências Geográficas, Universidade Federal de Pernambuco, Recife, 2010. Disponível em: $<$ https://www3.ufpe.br/posgeografia/images/documentos/d_2010_paulo_sergio_cunha_farias.pd f>. Acesso em: 25 abr. 2019.

FLAVIA ARANHA (São Paulo). Flavia Aranha: Roupas Vivas. Simples. 2019. Disponível em: <https://www.flaviaaranha.com/>. Acesso em: 20 maio 2019.

FLETCHER, Kate; GROSE, Lynda. Moda e sustentabilidade: design para mudança. São Paulo: Senac São Paulo, 2011. 192 p. Tradução de: Janaína Marcoantonio.

GREEN IS GREAT (Porto Alegre). Green is Great: Enxovais ecológicos. 2019. Disponível em: <https://www.greenisgreat.com.br/>. Acesso em: 20 maio 2019.

JUSTA TRAMA (Porto Alegre). Justa Trama Fibra Ecológica: Como Fazemos. 2019. Disponível em: <https://www.justatrama.com.br/sobre-nos/>. Acesso em: 26 abr. 2019.

LIRBÓRIO, Lúcia Ferreira. Sistema de produção de algodão naturalmente colorido na Paraíba (PB). Produção Acadêmica, Porto Nacional, v. 1, n. 2, p.3-17, dez. 2015. Disponível em: <https://sistemas.uft.edu.br/periodicos/index.php/producaoacademica/article/view/1994>.

Acesso em: 20 abr. 2019.

MANTUM. Mantum: Um presente de boas-vindas aos bebês. 2019. Disponível em: <https://www.mantum.com.br/transparencia>. Acesso em: 20 maio 2019.

MANZINI, Ezio; VEZZOLI, Carlo. O Desenvolvimento de Produtos Sustentáveis. São Paulo: Edusp, 2011. 368 p. Tradução de: Astrid de Carvalho.

NATURAL COTTON COLOR (Paraíba). Desfiles: Desfile Brasil Eco Fashion Week - 2017. 2019. Disponível em: <http://naturalcottoncolor.com.br/home>. Acesso em: 30 abr. 2019 
RETAMIRO, Wiliam; SILVA, José Luis Gomes da; VIEIRA, Edson Trajano. A sustentabilidade na cadeia produtiva do algodão orgânico. Latin American Journal Of Business Management, São Paulo, v.4, n.1, p.25-43, 25 de jun. 2013. Disponível em: <http://www.lajbm.net/index.php/journal/article/view/119>. Acesso em: 20 abr. 2019.

SOUZA, Maria Célia Martins de. A Produção de Têxteis de Algodão Orgânico: uma análise comparativa entre o subsistema orgânico e o sistema agroindustrial convencional. Revista Agricultura em São Paulo, São Paulo, v. 47, n. 2, p.83-104, 06 nov. 2000. Disponível em: $<$ https://www.researchgate.net/publication/237479716_A_PRODUCAO_DE_TEXTEIS_DE_ALGODA O_ORGANICO_uma_analise_comparativa_entre_o_subsistema_organico_e_o_sistema_agroindus trial_convencional1>. Acesso em: 20 abr. 2019.

TIMIRIM (São Paulo). Timirim: Projeto. Disponível em: <https://www.timirim.com.br/projeto/>. Acesso em: 20 maio 2019 